\title{
Discrepancias en el seno de la burguesía guipuzcoana en torno a la libertad de comercio y el traslado de aduanas durante los siglos XVIII y XIX*
}

\author{
Álvaro Aragón \\ Universidad del País Vasco
}

RESUMEN: El objetivo del presente artículo es demostrar y analizar las discrepancias que hubo en el seno de la burguesía guipuzcoana durante los siglos XVIII y $X I X$ en torno a la habilitación de los puertos guipuzcoanos para el comercio directo con América y el traslado de aduanas desde el interior a la costa. Para ello, se acude a la extensa historiografia que se ha ocupado del tema y se hace un análisis crítico de cierto número de representaciones enviadas por el grupo de comerciantes disidentes, con el fin de llevar a cabo un recorrido por el debate en torno a ambas cuestiones, que se prolongó desde el advenimiento de la dinastía borbónica hasta los decretos de 1841. A pesar de la visión unívoca que se ha dado del mencionado debate, según la cual participaron dos bloques perfectamente diferenciados, la documentación muestra una mayor heterogeneidad en las posturas, de manera que en el seno de la burguesía comercial se perciben ciertas divisiones y discrepancias. Si bien es cierto que en un principio los bloques parecen tener un discurso claramente beligerante, aunque también existen todavía puntos de coincidencia, a medida que transcurre el tiempo, las posturas se van radicalizando y diversificando, creando una mayor heterogeneidad.

PALABRAS CLAVE: Libre comercio; Guipúzcoa; burguesía; grandes comerciantes; pequeños comerciantes.

Disagreements among the bourgeoisie of Gipuzkoa about free trade and the transfer of customs from $18^{\text {th }}$ to $19^{\text {th }}$ centuries

* Siglas: Archivo Histórico Nacional: AHN; Archivo General de Gipuzkoa: AGG-GAO; Archivo Municipal de Oiartzun: AMO. 


\begin{abstract}
The aim of this paper is to demonstrate and to analyse the disagreements and the variety of opinions among the core of the bourgeoisie in Gipuzkoa, throughout the Ancient Regime, about the faculty of Basque ports to trade directly with American colonies and the transfer of the customs from the interior to the coast. So that, we will turn to the vast historiography focused on the issue and we will make a critical analysis of several reports sent by dissident merchants, to deepen into the debate about both topics, which developed from the beginning of the $18^{\text {th }}$ century to decree of 1841. Despite the univocal approach that Basque historiography has carried out, according to what only two blocks, perfectly different from each other, took part, the archival sources show a bigger diversity of the standpoints. Consequently, some disagreements and divisions can be notice inside the bourgeoisie. Although it is true that at the beginning of the debate these two blocks had a belligerent discourse, and despite there were some common agreements, as time went on, as a result of new political and economical circumstances of within Basque history, their positions became more radical and diverse, building a major diversity.
\end{abstract}

\title{
KEY WORDS: Free trade; Gipuzkoa; Bourgeoisie; Big tradesmen; Small tradesmen.
}

\section{INTRODUCCIÓN}

Tradicionalmente la cuestión en torno a la libertad de comercio, la habilitación de los puertos para el comercio directo con América y el traslado de aduanas en Guipúzcoa ha sido considerada un debate entre dos polos bien definidos y diferenciados. Por un lado, se situaría el bloque compacto de los comerciantes y burgueses donostiarras, alineados en torno al Consulado y al Ayuntamiento de la ciudad, favorables al traslado de aduanas y a la habilitación del puerto de San Sebastián para el comercio directo con América. Por otro lado, encontraríamos a las autoridades provinciales, básicamente visibles a través de su órgano permanente, la Diputación, en la que estaría representado lo más rancio, conservador e inmovilista -como la califica alguno de los autores que se citarán- de la nobleza rural guipuzcoana, totalmente contraria incluso a una modificación parcial del texto foral, más preocupada por salvaguardar sus propios intereses y la paz social, que pasaba por el mantenimiento de un sistema privilegiado que protegía a los consumidores, pero no a los intereses de especuladores y comerciantes ${ }^{1}$.

1 Sin ánimo de ser exhaustivos, todos los autores coinciden en esa visión dualista, desde obras clásicas como las de Fernández de Pinedo, Fernández de Albaladejo o Gárate Ojanguren, hasta trabajos más recientes como los de Aparicio Pérez, Rubio Pobes, Soria Sesé o Larrínaga Rodríguez. FERNÁNDEZ DE PINEDO, 1974: 342-349; 2, (San Sebastián, 1995): 56. FERNÁNDEZ ALBALADEJO, 1975: 243-244. GÁRATE OJANGUREN, 1976: 129; 9-10 
Sin embargo, un análisis profundo de la documentación pone en entredicho esta visión y muestra una realidad mucho más compleja, menos homogénea y más heterogénea, en la que se demuestra que en el grupo de comerciantes y burgueses existen actitudes que se alinean más con la facción representada por las autoridades provinciales, en contra de la habilitación del puerto de San Sebastián y el traslado de aduanas. Es ésta una realidad que comienza a manifestarse ya desde comienzos del siglo XVIII, coincidiendo con el advenimiento de la dinastía borbónica ${ }^{2}$. No obstante, son tres los momentos en que dicha diversidad y heterogeneidad se manifiestan con más claridad a través de la documentación: 1775-1778, 1833 y 1839.

\section{LAS PRIMERAS DESAVENENCIAS SURGIDAS DURANTE EL SIGLO XVIII}

Se hace preciso hacer una sucinta relación de los acontecimientos acaecidos hasta la aparición de los decretos de libre comercio en 1765 y 1778. Los comerciantes de San Sebastián intentaron, primero, la habilitación de los puertos vascos para el comercio directo con América, y, después, una vez comprobado lo ineficaz de tal medida, reclamaron el traslado de las aduanas a la costa y las fronteras del territorio. Fue el advenimiento de la dinastía borbónica el que provocó los primeros choques entre las ansias centralistas de aquella y la legislación foral. Aunque hubo intentos durante el siglo XVII de que la Corona autorizara el comercio directo con Indias desde los puertos vascos, fue en 1705 cuando los comerciantes de San Sebastián solicitaron por primera vez la habilitación de su puerto para el comercio directo con América, pagando los derechos reales, no en Cádiz, sino en el propio puerto donostiarra $^{3}$. En 1705 Miguel de Peredo, administrador de las rentas reales de lanas, había obtenido despacho real que le concedía privativa jurisdicción, con inhibición de los alcaldes, para visitar e inventariar en San Sebastián todas las lanas que había en los lavaderos, lonjas, almacenes y casas particulares de ella, con obligación para los comerciantes de mostrar los libros y de firmar los registros de las lanas cortadas entre 1700 y 1707. Aprovechando dicha prerrogativa, intentó cobrar cinco maravedíes de plata por cada pelleta de carnero o cordero de los que Guipúzcoa extraía fuera, cuando hasta la fecha se había acostumbrado a cobrar un cuartillo. El Consulado elevó sus quejas y

(San Sebastián, 1988): 37. APARICIO PÉREZ, 1991: 163. RUBIO POBES, 1996a: 17; 1996b: 91-126. SORIA SESÉ, 2 (San Sebastián, 2003): 453-477. LARRÍNAGA RODRÍGUEZ, 21 (Murcia, 2005): 324.

2 ALBERDI LONBIDE, 2006: 809-830.

3 AGG-GAO, JD IM 2/22/58 y 59. ALBERDI LONBIDE, 2012: 586-587. GÁRATE OJANGUREN, 1988: 36-37. 
solicitó que se denegasen los registros y visitas, que suponían un contrafuero. Ese mismo año, las Juntas Generales de Segura solicitaron al rey el derecho de 300 toneladas anuales para transportar hierro y demás frutos de la tierra a los puertos de Indias, menos a los reservados a las Armadas y la flota de Galeones (Cartagena, Portobelo y Veracruz) y que las lanas bajasen de Aragón y Navarra a San Sebastián y Pasajes. Se mandó comisión a la corte con Juan de Olazábal. Pero en ese momento los andaluces pretendieron impugnar dicha pretensión alegando que, de no pagarse los derechos en Guipúzcoa, se perjudicaba al rey, aunque, como mantenía Olazábal, en Guipúzcoa se pagaban los derechos de la lana y la alcabala. La Diputación pidió a San Sebastián que crease una comisión para estudiar cómo se podrían cobrar derechos a los productos procedentes de América, a lo que la ciudad respondió que se pagarían todos los derechos igual que se pagaban en el resto de puertos, puesto que, como era conocido, aunque no tenía aduanas, el hierro pagaba derechos en Sevilla y Cádiz, por lo que pagar derechos en San Sebastián no era perjudicial, evitando tener que pagar en dichos puertos, riesgos, fletes y seguros. También los coloniales venían pagando derechos en ambos puertos, siendo transportados posteriormente a Guipúzcoa. San Sebastián alegaba entonces que en caso de que los productos llegasen sin escala sería más beneficioso, sin que el derecho de alcabala fuese realmente gravoso. Entre tanto, las Juntas Generales del año 1706 establecieron que en caso de obtener la libertad de comercio con Indias, se procurase que los derechos no excediesen de los cobrados hasta ese momento. Sin embargo, dicho propósito no se logró, pues el pago de más derechos se tuvo finalmente por incompatible con los fueros.

Tras el conflicto aduanero entre 1717 y 1722, se estableció un capitulado entre la Corona y Guipúzcoa el 8 de noviembre de 1727 que reconocía a Guipúzcoa la libertad de introducción de bastimentos para su comercio o consumo dentro de su territorio y conservaba el arancel establecido desde el año 1680 para los productos extraídos a Navarra ${ }^{4}$. Para entonces ya se había iniciado el proceso de establecimiento de la Real Compañía de Caracas, fundada en 1728 -no sin grandes reparos por algunos sectores-, que contó con el favor del ministro José Patiño. Finalmente se concedió el permiso de comercio con Caracas, bajo la condición de que a la vuelta el navío hubiese de pasar por Cádiz, donde pagaría los derechos exigidos. La primera propuesta, sin embargo, fue que los navíos de la compañía saliesen y llegasen a Cádiz, para evitar los fraudes y la disminución de derechos. La Diputación protestó esta propuesta por las dificultades que ello comportaba, los costos y la corta utilidad de los hierros que se hubiesen transportado. Por ello las autoridades provinciales solicitaron que la salida se realizase desde los propios puertos, pasando

\footnotetext{
4 ALBERDI LONBIDE, 2006: 781-783. FERNÁNDEZ ALBALADEJO, 1975: 51-52.
} 
registro el juez de arribadas de San Sebastián. Se propuso contribuir al rey por vía de servicio con una cantidad equivalente a los derechos que percibiría caso de salir de otros puertos, según el Real Proyecto de 1720, y a los derechos de llegada, a excepción del cacao y demás productos que se fuesen a consumir en la provincia. De esta forma, las franquezas de Guipúzcoa quedaban a salvo, aunque no pasaron muchos años hasta que se experimentaron novedades desagradables. Por Real orden de 3 de septiembre de 1742, habiendo arribado la fragata San Vicente a Ribadeo con cacao, que fue vendido en su almacén, pretendió el administrador de las alcabalas del partido de El Ferrol que se le pagasen derechos, cuando esto estaba incluido en los 33 maravedíes/libra que se abonaban. En 1753 una Real Orden establecía la intervención en cada barco de la Compañía de Caracas del juez de arribadas, el contador de reglamentos y uno o dos guardas, en el momento en que la Real Compañía de Caracas había escapado al control de la Diputación, pues su sede se había trasladado en 1751 a Madrid.

En 1765 llegó la primera decepción para los comerciantes de San Sebastián, puesto que el decreto de libre comercio con América marginaba a los puertos vascos. No obstante, parece que la preocupación no cundió de momento entre ellos, gracias sobre todo a las ventajas que seguiría reportando la Real Compañía de Caracas hasta 1784. En 1771 el Consulado de San Sebastián, a una con los cosecheros navarros, presentó ante las autoridades provinciales su pretensión de extraer los frutos sobrantes de aquel reino por San Sebastián hacia América, a lo que los consultores y la Diputación se opusieron por ser contrafuero. El mismo punto se volvió a tratar el 7 de julio de $1772^{5}$. El primer enfrentamiento entre los propios comerciantes ya se produjo a mediados de la década de los años setenta. Con motivo del proyecto de nueva dársena en el puerto de San Sebastián, el Consulado de San Sebastián decidió aplicar una contribución de medio por ciento de derecho de Avería a los comerciantes. Todo comenzó el día 29 de octubre de 1775, cuando el Consulado, formado por el prior Juan Domingo de Huici, los cónsules Juan Ignacio Ibáñez de Zabala y Juan José Vicente de Michelena, el síndico Manuel Francisco de Irurtia, los consultores Diego de Echagüe, Francisco Ignacio de Goicoechea y Juan de Michelena, estableció un decreto para que los comerciantes, capitanes, dueños de mercaderías, receptores de ellas y consignatarios diesen razón firmada al recaudador del derecho de Avería, antes de que se verificasen las descargas, para que éste tomase cuenta exacta en el libro del número de piezas o el peso. Esta decisión, que afectaba esencialmente al cacao de Caracas y Guayaquil, al azúcar de la Habana y a los cueros al pelo procedentes de Buenos Aires, contrarió a muchos comerciantes de San Sebas-

\footnotetext{
5 AGG-GAO, JD IT 575 0, 5.
} 
tián, sobre todo a aquellos que precisamente mantenían importantes conexiones comerciales con América, y provocó disensiones entre estos y los dirigentes del Consulado. Los primeros trataban de economizar al máximo el tráfico de sus mercancías, mientras que los segundos exigían a los primeros transparencia en sus abonos, para obtener los ingresos necesarios para acometer las obras proyectadas. Los comerciantes presentaron un memorial solicitando la convocatoria de junta general, solicitud a la que accedió el Ayuntamiento. No obstante, esta decisión provocó la protesta de los regidores José de Guruceaga y Juan José de Goicoechea, pues las juntas se celebraban tradicionalmente en el Consulado y no en el Ayuntamiento. Dichas protestas surtieron efecto, puesto que el comandante general solicitó al alcalde de San Sebastián, José de Olózaga, que se suspendiera. Al día siguiente, el día 30 de octubre se celebró una Junta de Comerciantes, con la asistencia del licenciado Pedro Miguel de San Juan, el síndico Manuel Francisco de Irurtia, los consultores (Diego de Echagüe, Juan José Zuáznabar, Juan Ignacio de Zabala, José Ignacio de Goicoechea y Juan José Vicente de Michelena) y seis comerciantes, a resultas de la cual se aprobaron los acuerdos tomados por el prior y cónsules.

CUADRO 1: FIRMANTES DE LA PROTESTA SOBRE LOS DERECHOS DE AVERÍA ENVIADA A LA CORTE (1776)

\begin{tabular}{|c|c|c|}
\hline Aizcorbe, Fermín de & Albi & Aranalde, José Ventura de \\
\hline $\begin{array}{c}\text { Arangua, Miguel Fran- } \\
\text { cisco de }\end{array}$ & Arbaiza, Nicolás Antonio de & $\begin{array}{c}\text { Armendáriz, José Ignacio } \\
\text { de }\end{array}$ \\
\hline Arpide, José Ignacio de & Artola, Alejandro de & Bermingham, Ricardo de \\
\hline Betbeder, Antonio & Blandín hermanos & $\begin{array}{c}\text { Bordachipia, Mateo Mi- } \\
\text { guel de }\end{array}$ \\
\hline Bousignac, Juan de & Carrera, José Ignacio & Carrera, Juan \\
\hline $\begin{array}{c}\text { Dabadie y Larrache, } \\
\text { Viuda de }\end{array}$ & Demblans, Juan & Duble, Bautista Joaquín \\
\hline Eceiza, Joaquín de & Echeverría, Agustín de & Elizondo, Fermín de \\
\hline Espilla, José de & Fernández de Madrileño, & Francine, Diego \\
\hline Gainza, Bernardo de & Galain, Juan Fermín de & Garde, Joaquín \\
\hline $\begin{array}{c}\text { Garnier, Miguel Fran- } \\
\text { cisco de }\end{array}$ & Goicoa, José Miguel de & $\begin{array}{c}\text { Goicoechea, Juan Ramón } \\
\text { de }\end{array}$ \\
\hline Gruet, Santiago & Guruceaga, José de & Huici, Juan Bautista de \\
\hline $\begin{array}{c}\text { Illarramendi, Ignacio } \\
\text { de }\end{array}$ & Laquidain, Miguel Fermín de & Larralde Duistegui, Pedro \\
\hline $\begin{array}{c}\text { Larralde Duistegui, } \\
\text { Francisco }\end{array}$ & Larreandi, Francisco Javier de & $\begin{array}{c}\text { Lizarraga, Martín Ezquer } \\
\text { de }\end{array}$ \\
\hline
\end{tabular}




\begin{tabular}{|c|c|c|}
\hline Lodón, Marcos & Lone, Juan & Mendinueta, Juan José de \\
\hline Mila, José de & Noguez, Bernardo & Rieumes y Burgue \\
\hline Roca, José Mila de la & Sancho, Julián & Sexton, Felipe \\
\hline Sort, Tomás de & Tastet, Antonio & $\begin{array}{c}\text { Urbistondo, José Antonio } \\
\text { de }\end{array}$ \\
\hline $\begin{array}{c}\text { Zuaznavar, Juan José } \\
\text { de }\end{array}$ & Zubirán, Francisco de & \\
\hline
\end{tabular}

Fuente: ASTIAZARÁN ACHABAL, 1998: 156-167. ALBERDI LONBIDE, 2012: 1150.

La protesta de los comerciantes se materializó el día 3 de noviembre, siendo presentada por Juan de Carrera, en nombre de otros 54 comerciantes más. El día 26 de noviembre el Prior y Cónsules escribieron una carta al Marqués de Basecourt, comandante general de la provincia de Guipúzcoa, dándole cuenta de todo lo acaecido. Un día después, el 27 de noviembre, Miguel Francisco de Barcaiztegui, alcalde y juez ordinario de San Sebastián, aportaba a Manuel Francisco de Irurtia, síndico de la casa de Contratación, una copia del memorial presentado por Francisco Larralde Duistegui y otros comerciantes solicitando licencia para llevar a cabo su junta en la sala consistorial. Todo el conflicto trascendió a la Corte y se inició un recurso ante el Consejo de Castilla que duraría hasta 1778. A finales de 1775 se eligió un nuevo equipo rector del Consulado que hubo de afrontar el proceso: Juan de Michelena fue elegido prior, Diego de Echagüe y Juan José de Mendinueta cónsules, Juan José Vicente de Michelena, Juan Ignacio Ibáñez de Zabala, Juan José de Goicoechea y Francisco Ignacio de Pollo y Sagasti consultores. A comienzos de 1776 los comerciantes, muchos de ellos miembros del Consulado y encabezados por Mateo Miguel de Bordachipia, Ignacio de Carrera y Francisco Larralde Duistegui, enviaron a la corte una carta sobre el tema del pago de derechos de Avería, solicitando que se hicieran como de costumbre y no como pretendía el anterior prior y cónsules, quienes habían intentado cambiarlo sin la aprobación de la junta general. Como se puede comprobar a través de la lista que aporta el cuadro 1, un gran número eran franceses, habilitados para la venta de tabaco americano y con importantes relaciones comerciales con el continente americano ${ }^{6}$. Se debe tener en cuenta, que el aumento de derechos se unía a los que ya se pagaban en los puertos habilitados, por lo que tal medida aumentaba los costos y reducía el margen de beneficio de estos comerciantes.

El conflicto surgido en el seno del Consulado acabó enfrentando a éste con el Concejo, quien a su vez tuvo sus desavenencias con el comandante general.

\footnotetext{
6 ARAGÓN RUANO, 31 (Salamanca 2009a): 183-197.
} 
En definitiva, se formaron dos partidos opuestos entre sí. El conflicto se trasladó incluso al concejo de San Sebastián, puesto que el nuevo alcalde, Bernardo de Gainza, era cuñado de José Ignacio de Carrera, regidor, quien junto al otro regidor, Mateo Miguel de Bordachipia, eran comerciantes, mientras que el tercer regidor era José Domingo de Huici, el prior saliente. Pero también tuvo su influjo en el propio Consulado, donde había disparidad de pareceres. Las intenciones de los comerciantes no prosperaron y se vieron obligados al pago de la Avería; esta derrota provocó que desde entonces la mayoría de ellos, como Juan José de Zuáznavar o Ignacio Antonio de Lopeola, se alinearan claramente a favor de la habilitación y el traslado de las aduanas, frente a aquellos que, como Juan José Vicente de Michelena, se oponían a ambas medidas y habían promovido los mencionados derechos ${ }^{7}$.

El revés obtenido del Consejo de Castilla se sumó a toda una serie de aparentes inconvenientes y obstáculos que se producirían a partir de entonces. En primer lugar, el decreto de libre comercio del año 1778, del que nuevamente San Sebastián quedaba excluido, o la consideración del hierro vasco y productos extraídos de las provincias exentas como extranjeros en los mercados peninsulares desde 1779. En este contexto, precisamente, nació en enero de 1779 la Sociedad de Amigos del País de San Sebastián, auspiciada por Manuel Antonio de Arriola y Corral, Francisco Javier de Leizaur, Manuel Ignacio de Aguirre, Ignacio Antonio de Lopeola, Francisco Ignacio de Pollo y Sagasti y Juan José de Zuáznavar, de la que formarán parte un numeroso grupo de comerciantes donostiarras, muchos de ellos también miembros de la Real Sociedad Bascongada de Amigos del País. Entre sus miembros estaban, por supuesto, los comerciantes protagonistas de la disputa en torno a los derechos de Avería, por un lado, Juan José Vicente de Michelena y José Domingo de Huici, y por otro, José Miguel Goicoa, Fernando Vicente de Ansorena Garayoa, José Ignacio Carrera, Francisco Javier de Leizaur, José Ventura Aranalde, y los mencionados Ignacio Antonio de Lopeola y Juan José Zuáznavar.

Estos dos últimos, junto con Juan José Vicente de Michelena, formaban parte también de la Real Sociedad Bascongada de Amigos del País, donde ya en 1778, a raíz del decreto de libre comercio, protagonizaron una disputa en torno a la conveniencia o no de la habilitación de San Sebastián para el comercio con América ${ }^{8}$. Zuaznavar y Lopeola respondieron al escrito previo de Michelena manifestando que quienes estaban interesados en el sistema imperante «...son un puñado de particulares mientras caminan a su destrucción todas las demás clases de gentes del país bascongado.». En su respuesta eran

7 AHN, Consejos Suprimidos, Consejo y Cámara de Castilla, Salas de Justicia, Escribanía de Cámara de Granados, 27207 / 1. ALBERDI LONBIDE, 2012: 1150. ASTIARAZÁN ACHABAL, 1988: 156-167.

8 DOMÍNGUEZ, 1988: 252-253. 
conscientes de la existencia de dos grupos bien definidos: por un lado, Michelena mantenía las tesis que los consultores de la provincia habían manifestado en la Junta General de Hernani, el 7 de julio de 1772, de que las medidas que se pretendían suponían un contrafuero; por otro lado, estaba el resto de amigos del país, los capitulares y diputados del común de San Sebastián, el prior, cónsules, consultores, síndico y junta general del Consulado, quienes se alineaban a las tesis de la Junta general celebrada en 1705 en Azpeitia, a favor de la habilitación del puerto de San Sebastián. Michelena defendía que con el sistema imperante los productos importados eran más baratos, pues no se pagaban tan elevados derechos, gracias a la libertad de importación que poseía la provincia para productos de consumo propio. Zuaznavar y Lopeola le replicaban que, aún siendo eso cierto, el problema surgía cuando se querían introducir dichos productos en el resto de la Corona, pues debían pagar elevados derechos en las aduanas interiores, no pudiendo competir con los que se introducían por los puertos habilitados. Ambos comerciantes proponían, como hizo el Consulado, adoptar el método seguido por la Real Compañía de Caracas, es decir pagar por vía de servicio a la Real Hacienda, pudiendo ahorrarse de esa forma los fletes, seguros y demás gastos derivados de las escalas. No parecía estar de acuerdo con esta propuesta Michelena, pues consideraba que aunque la Real Compañía de Caracas sí evitaba el fraude, el sistema propuesto no lo podría conseguir, ya que en el primer caso los productos salían y llegaban al almacén de la Compañía, mientras que en el segundo caso, aunque saliesen del almacén del Consulado, como se proponía, los productos llegarían a los almacenes de los particulares, donde no podrían ser verificados y evitado el fraude; esto llama poderosamente la atención, más aún teniendo en cuenta que Michelena estaría encausado en 1784 por un caso de contrabando y que en 1786 buscó asilo en Francia ante la quiebra de la sociedad comercial que formaba con Francisco Aldaz ${ }^{9}$. Aunque Michelena consideraba contrafuero el establecimiento de una aduana formal en la costa, Zuaznavar y Lopeola le replicaban preguntándose porqué entonces se venían pagando los derechos de la lengua de mar en el caso de la lana. Según Michelena los beneficios del comercio directo no eran comparables a los que reportaba la Real Compañía de Caracas. Por último, Michelena consideraba de menor costo el sistema imperante, a través de los puertos habilitados, que los perjuicios que reportaría a corto y largo plazo la propuesta del Consulado. En respuesta, Zuaznavar y Lopeola presentaban el caso del navío San Pedro Apóstol, propiedad de Pedro Larralde Duistegui e hijo, que el 20 de diciembre de 1775 salió desde San Sebastián a Luisiana, el cual a consecuencia de la escala que debió hacer en el puerto habilitado de Santander tuvo un costo adicional de

\footnotetext{
9 MIGUEL LÓPEZ, 39 (San Sebastián, 2005): 262.
} 
34.260 reales. De haber viajado directamente se hubiese ahorrado, además de los peligros del mar, el perjuicio de cargar y descargar los productos en dicha escala y tres meses de navegación. Un problema añadido del sistema imperante era que los fondos se debían anticipar y los beneficios podían llegar a ser menores, debido al retraso y a la competencia de aquellos que viajando directamente podían cubrir antes la demanda de los mercados. En lo que sí parece que coincidían ambas partes es en el rechazo, al menos momentáneo, del traslado de aduanas al mar ${ }^{10}$.

Posteriormente, la situación se recrudeció ante los abusos del Juez de Contrabando Juan Antonio Enríquez, desde que llegase a San Sebastián el 12 de junio de 1785, la desaparición de la Real Compañía de Caracas en 1784, la franquicia de Bayona entre 1784 y 1790, la prohibición de extraer cacao, azúcar y otros coloniales a Navarra entre 1786 y 1793, y el arancel impuesto en $1789^{11}$. Fueron esos abusos, la negativa a la habilitación por parte de la Corona, si no mediaba el traslado de aduanas, y la falta de apoyo de las instituciones provinciales lo que radicalizó las posturas de los comerciantes hacia el año 1789, sobre todo frente a las instituciones provinciales. Por esas fechas se redactaba un anónimo en tono crítico, titulado Carta en glovo escrita a vn Guipuzcoano por vn sugeto forastero Amigo suyo, sobre la circular que pasó la diputación de su Provincia a las Repúblicas de su distrito, en que se toca como de paso mui por encima la que escribió otro Guipuzcoano a dos Paisanos suyos, y que se halla en el espiritu de los mejores Diarios literarios que se dio a la luz en 15 de junio de 1789, en respuesta a la circular enviada por la Diputación de Guipúzcoa, publicada en Azpeitia el 8 de junio de 1789, en torno a la complementariedad entre los Fueros y la habilitación de los puertos $^{12}$. Dicho texto es firmado el 30 de julio de 1789 por un tal don Prudencio Prevenido y don Casimiro Vigilante. ¿Cabría sospechar que el mencionado sujeto forastero era un extranjero avecindado o un transeúnte?, ¿francés tal vez? Y en ese caso, ¿alguno de los firmantes de la protesta sobre la Avería enviada a la corte en 1776? Desgraciadamente no nos hallamos en disposición de negarlo o aseverarlo, aunque sin duda sería cercano a ese círculo cuyas tesis abogaban por la habilitación. Lo importante del texto es la percepción de que hay formados ya dos claros bandos y de que la Diputación prefiere apo-

10 EXTRACTOS, 1779: 92-126. AGG-GAO, JD IT 4248b, 11.

11 JAUPART, 1966-1974, vol. 2: 375-377. LARRÍNAGA RODRÍGUEZ, 21 (Murcia, 2005): 324-330.

12 AGG-GAO, SS 99. AMO, A, 1, 70, 2, fol. $109 \mathrm{r}^{\circ}$ - $110 \mathrm{v}^{\circ}$. AGG-GAO, JD IM 2/22/108. Curiosamente en oficio enviado desde Cádiz el 24 de noviembre 1789, Xavier Ignacio de Amenabar informaba haber realizado una encuesta entre los comerciantes guipuzcoanos en la ciudad Andaluza, sobre la conveniencia de llevar a cabo la petición del Consulado y del Ayuntamiento de San Sebastián, y todos la desaconsejaban, lo cual es lógico puesto que de habilitarse el puerto de San Sebastián, se quebraría el eje Cádiz-San Sebastián. 
yar al bando fuerista. La crítica, por tanto, únicamente se dirige hacia la Diputación, no hacia las Juntas Generales o el rey, Carlos IV, al que muy al contrario alaba y loa, calificándolo de monarca «...tan católico, tan piadoso, tan benigno y liberal...Augusto padre del que hoy tan dignamente nos rige y govierna, acreditando en todas sus acciones, que no menos ha sido heredero de sus virtudes, que de su Monarquia, no se de digno declarar otra cosa...». Con el tiempo esa perspectiva hacia el monarca cambiaría, al menos entre un sector del grupo favorable a la modificación, que se radicalizaría y, haciendo suyas las máximas revolucionarias, lo calificaría de déspota.

Coincide este libelo con el debate sobre la prohibición de comercio con Navarra en 1789, que finalmente sería permitido en 1793, pues menciona que dicho reino podría aportar 300.000 celemines de trigo, 200.000 cargas de vino, 37.000 celemines de maíz, 40.000 arrobas de lana y grandes cantidades de aceite, cáñamo, alubias y otros frutos, todo ello facilitado por los caminos que estaban en construcción y a punto de ser finalizados. Se queja amargamente de que las reticencias de las autoridades provinciales, junto a otras medidas, hubiesen provocado la ruina del comercio de San Sebastián, de lo que se había beneficiado Bayona. Es curioso este alegato, puesto que, como veremos, se volvió a repetir en los años treinta del siglo XIX, en circunstancias bastante diferentes.

Personifica en la Diputación la oposición a los proyectos de los comerciantes -a los que presenta como un bloque unitario-, ya que en las Juntas Generales la opinión parece ser diferente. Poco a poco va radicalizando su discurso, afirmando, en clara referencia a la Diputación, «...que las cosas de comercio no son para todos.». Tras recordar el rechazo manifestado por la Diputación al articulado presentado por los comisionados de la Ciudad y Consulado de San Sebastián, y los desvelos de la Real Sociedad Bascongada de Amigos del País ${ }^{13}$, llega al momento cumbre del discurso desautorizando a la Diputación por su inmovilismo:

Tuvo la Diputación otro distinto plan concebido en ventajas del País, para reparacion en parte de su necesidad, y miseria, precaviéndose en él todo temor de Aduana (Monstruo formidable sin cabezas ni colas de que la Diputación huye teniéndolo en su casa) y tambien abandonó este plan; iQué es esto! Tanto fuero rozado, como se ve, la libertad arruinada, el comercio abatido, la industria aniquilada, golpe sobre golpe, traba, sobre traba, no se procura alivio, y el que se propone, nada hace, nada discurre, a nada se muebe, y a todo se hace insensible. ¿Qué Diputación es esta? Por eso dige no sabe lo que quiere, no lo entiende, ni lo quiere entender, y que las cosas de comercio no son para todos.»

13 ASTIGARRAGA, 2003: 176-202. 
Parece además como si hiciese toda una declaración de intenciones, aviso a navegantes o predicción, puesto que preveía lo que iba a ocurrir cinco años después, durante la ocupación de las tropas de la Convención francesa -en la que los mencionados comerciantes franceses iban a tener un papel tan relevante-, lo cual muestra así mismo el ánimo del partido al que representa ${ }^{14}$ :

...y vaya vn simil. La plaza de Bilbao se halla sitiada; pero con gente, viberes, y fuerzas para resistir a los invasores. La plaza de San Sebastián se halla tambien sitiada, mas con brechas abiertas, decaidas las fuerzas, y poseída del hambre. ¿Qué hará San Sebastián en tan apretado lance, sino clamar y lebantar el grito pidiendo auxilio y socorro, o vna capitulación honrosa? Al contrario Bilbao, que pudo y puede por si sola defenderse, ya me explico.

Lo que tiene claro el autor del texto es que un territorio que compra más de lo que vende y, por tanto, saca más dinero del que entra, camina precipitadamente a su ruina, si con el comercio y la industria no lo repara. Solicita el libre comercio como medio más eficaz de defender los fueros, sin que éstos se conviertan en mero papel por su ineficacia y poca practicidad, para lo que pone como ejemplo a Cataluña, que, desde que sus fueros fueron abolidos y establecidas las aduanas en sus puertos, ha entrado en una franca expansión, y a Holanda, que, sin tener productos propios, es el almacén del mundo gracias a que cuenta con puertos, hombres, "comercio ancho, libre, activo y pasivo».

La última parte del exhorto lo dedica a la efectividad de los fueros y a la necesidad de su modificación, ámbito en el que ya se da un paso más con respecto a las reivindicaciones efectuadas en 1778 , puesto que se solicita también el traslado de las aduanas a la costa:

Según la constitución de Guipúzcoa, puede asegurarse estamos engañados sobre varios puntos con mas ventajas imaginarias que realmente no tenemos, y que desatendemos las reales, y efectivas que nos resultarán precisamente de abrazar algun proyecto...Yo no encuentro alguno (remedio) que sea mas del caso, que la traslación de las Aduanas a los Puertos como el Rey lo ha deseado...que para el libre comercio de America se habiliten los puertos de San Sebastián y Pasages, sin mas gravamen en sus frutos, manufacturas, y demas efectos de comercio que el prescrito a los demas Puertos habilitados, y a los españoles que desde ellos hacen el mismo comercio: que de todas partes venga a Guipúzcoa el oro y plata que antes venia, cesando enteramente y desde luego la prohibición que para introducirle hasta aquí ha habido, y asi mismo las guias que se dan de poco tiempo a esta parte, para el dinero de Pueblo a Pueblo: que los generos estancados en Castilla, que se hallan libres en Guipúzcoa, queden en el mismo estado de libertad que hoy

14 Sobre ese acontecimiento véase GOÑI GALARRAGA, 1979, vol. 3: 5-69; 1985: 247294. OTAZU Y LLANA, 1982. PORTILLO VALDÉS, 12 (Salamanca, 1994): 71-90. 
tienen...sin que de ningun modo se infiera de ello, que se renuncia derecho, ni prerrogativa alguna de las demas que comprenden los Fueros, y exenciones de Guipúzcoa sino que antes bien han de quedar todas ellas en su fuerza, y vigor, continuando con su antigua libertad, y en la justa y pacífica posesion de proponer al Soberano, las leyes que estime.

Todo un alegato, que se adelantaba casi cuarenta años a lo que algunos autores consideran la primera muestra de ruptura clara con las autoridades provinciales, con la aparición en 1832 de la Memoria justificativa.

En cualquier caso, frente a los supuestos reveses, los comerciantes donostiarras, tanto los favorables como los contrarios a la habilitación del puerto y al traslado de aduanas, supieron arbitrar, tanto en el siglo XVIII como en el XIX, alternativas que les reportaron importantes beneficios -incluso mayores de los que hubiesen obtenido de producirse la habilitación-. Por un lado, siguieron desarrollando su actividad comercial con Europa y América, a través de los navíos de la Real Compañía de Caracas, primero, y de la Real Compañía de Filipinas, después, que siguió operando en San Sebastián, o por medio de registros sueltos hasta los decretos de libre comercio, a través de los puertos peninsulares habilitados, caso de Santander y Cádiz, o de los puertos franceses de Bayona y Burdeos ${ }^{15}$. Se debe tener en cuenta que, como ha puesto de relieve John Fisher, entre 1778 y 1796, y a pesar de las habilitaciones, Cádiz mantuvo en torno al $76 \%$ del total de exportaciones a América ${ }^{16}$. Además de ello, se beneficiaron de las habilitaciones para la venta de tabaco, el préstamo de capitales a interés a las arcas provinciales y a particulares (campesinos, emigrantes a América, pago de dotes o pequeños tenderos), la importación de grano y harinas, el tráfico y especulación de granos en el interior de la provincia, el abastecimiento de carne y trigo a los ejércitos franceses, y, tal vez el más benefícioso -aunque difícil de calibrar-: el contrabando ${ }^{17}$.

\section{LA RUPTURA DEL SIGLO XIX: ¿GRANDES COMERCIANTES FRENTE A MEDIA- NOS Y PEQUEÑOS COMERCIANTES?}

Precisamente, había llegado a tal nivel el problema del contrabando a finales del siglo XVIII y comienzos del siglo XIX que una Real Orden de 6 de noviembre de 1815 estableció una Junta de Reforma de Abusos de la Real Hacienda de las Provincias Vascongadas, encargada de llevar a cabo un in-

15 ARAZOLA CORVERA, 4 (San Sebastián, 2003): 327-342. DÍAZ TRECHUELO, 1965. GÁRATE OJANGUREN, 1990; 1993. PONTET, 1990: 63, 74; 1994: 25-41.

16 FISHER, 1985, 1: 39; 1987: 30.

17 AGG-GAO, JD AIM 551 y JD CO 52 y 53. ARAGÓN RUANO, 2009b: 323-329; 354-370. MUGARTEGUI EGUÍA, 4 (San Sebastián, 2003): 388-393. 
forme sobre el fraude y proponer las medidas necesarias para erradicarlo. El 10 de julio de 1817 otra Real Orden gravó con derechos adicionales la introducción de productos coloniales en Castilla y Aragón desde las provincias vascas, que se sumaban así a los que ya se pagaban en los puertos habilitados de los que procedían, y prohibió la introducción en Navarra de coloniales procedentes de San Sebastián que fuesen desembarcados en navíos extranjeros. Con la llegada del gobierno liberal del Trienio, decidido a crear un mercado nacional, el 1 de enero de 1821 se trasladaron los registros aduaneros a la costa y a la frontera con Francia, aunque el corto período de gobierno no permitió vislumbrar los beneficios de la medida. La restauración fernandina, tratando de frenar el contrabando, dio marcha atrás y por Real Orden de 2 de diciembre de 1824 prohibió la introducción de productos coloniales en España desde el puerto de San Sebastián, lo cual perjudicó notoriamente a muchos comerciantes de la ciudad, puesto que tenían almacenadas grandes cantidades, que finalmente se perdieron. Sin embargo las reivindicaciones a favor del libre comercio obtuvieron un éxito parcial en 1828, cuando una Real Orden promulgada el 21 de febrero habilitó temporalmente los puertos de San Sebastián y Bilbao para el comercio directo con América, bajo la jurisdicción de la Dirección General de Rentas. No obstante, esta medida contó con la oposición de Santander, cuyo Ayuntamiento envió una representación al Rey en 1829 , en la que insistía en la necesidad de que la habilitación de los puertos vascos debía ir acompañada de la creación de aduanas y resguardos, para no perjudicar al resto de territorios, puesto que en caso contrario el contrabando aumentaría peligrosamente, ya que «...se trata de unas provincias, cuios comerciantes, eceptuados algunos pocos, labran su fortuna en el trafico de generos de Contrabando.» ${ }^{18}$.

La alegría no les duró demasiado a los comerciantes partidarios de la habilitación, puesto que una Real Orden de 29 de enero de 1830 otorgaba el control de los nuevos tribunales de comercio a las diputaciones vascongadas. En 1831, durante la celebración de las Juntas Generales de Azpeitia, los representantes de San Sebastián presentaron una Exposición del Ayuntamiento y la Junta de Comercio, en la que ya se atrevían a criticar abiertamente el sistema foral. La respuesta de las autoridades provinciales fue muy dura, rechazando de plano sus reivindicaciones. La comisión encargada de estudiar la exposición daba por supuestos los «funestísimos» resultados que tendría el traslado aduanero para los consumidores y planteaba serias dudas sobre el efecto positivo que tendría sobre la industria y el comercio. En esta línea, dichos comisionados reconocían lo beneficioso del traslado en el caso de los grandes co-

18 APARICIO PÉREZ, 1991: 165-160. LARRÍNAGA RODRÍGUEZ, 21 (San Sebastián, 2005): 330-337. LLANOS ARAMBURU, 1998: 152-155; 232-237; RUBIO POBES, 1996a: 20-30. 
merciantes, pero consideraban que los medianos y pequeños comerciantes, cuyo número era mucho más elevado, se verían fuertemente perjudicados por el cambio arancelario ${ }^{19}$. Esa es precisamente la clave de las disensiones en el seño de la burguesía donostiarra durante el siglo XIX: lo que era beneficioso para la minoría de grandes comerciantes era perjudicial para la mayoría de medianos y pequeños comerciantes. Lo mismo ocurrió en el caso vizcaíno, como apunta Fernández de Pinedo, donde el definitivo traslado de las aduanas a la costa en 1841 supuso un duro golpe para el tráfico de importaciónexportación. En Bilbao afectó negativamente al pequeño comercio, mientras que «las casas más poderosas» obtuvieron algunas ventajas en las transacciones con las colonias y antiguas posesiones de América ${ }^{20}$.

La reacción de San Sebastián fue convocar una reunión de vecinos concejantes, en la que se manifestaría su decisión de obrar independientemente con respecto a las autoridades provinciales, lo cual certificaba ya la ruptura y un claro alejamiento entre ambas partes. Curiosamente, en la junta de vecinos concejantes hubo un sector, representado por el también comerciante Alejandro de Burgué, que discrepó abiertamente de las decisiones adoptadas por la misma, puesto que era partidario de anteponer la conservación íntegra de los fueros a cualquier beneficio mercantil. Dicha junta tomó tres decisiones. En primer lugar, crear una comisión formada por Joaquín de Mendizábal y José María Sáenz Izquierdo, propietarios, y José Antonio Fernández Garayalde, comerciante, junto a Pedro María Queheille y José Manuel Brunet, comerciantes nombrados por la Junta de Comercio. En segundo lugar, se envió a la Corte al abogado liberal Claudio Antón Luzuriaga, para promover la habilitación del puerto de San Sebastián, de manera independiente del agente en corte de la provincia. En tercer lugar, en mayo de 1832 se publicaba la famosa Memoria justificativa de lo que tiene expuesto y pedido la ciudad de San Sebastián para el fomento de la industria y comercio de Guipúzcoa, cuyo autor parece ser el propio Luzuriaga. Los trámites de Luzuriaga surtieron efecto puesto que el 14 de noviembre de 1832 una Real Orden hacía efectiva la habilitación del puerto de San Sebastián para comerciar directamente con América y establecía un reglamento, que supuso la creación de una Oficina de Administración en el puerto, para el cobro de derechos a los coloniales, la introducción de estos en Castilla, previa guía, la confiscación de aquellos que no la obtuviesen, y el pago de derechos de extranjería para el resto de productos. Sin embargo, el 29 de marzo de 1833 el Rey suspendió dicha Real Orden, hasta oír a las autoridades provinciales ${ }^{21}$.

19 APARICIO PÉREZ, 1991: 175.

20 FERNÁNDEZ DE PINEDO, 1974: 344.

21 APARICIO PÉREZ, 1991: 151-191. LARRÍNAGA RODRÍGUEZ, 21 (Murcia, 2005): 340. RUBIO POBES, 1996a: 30-47. 
En respuesta a dicho folleto, a la Exposición de 1831, a la Real Orden de 1832 y a la suspensión de 1833 , el 5 de julio de 1833 veinte comerciantes hacían relación de las causas que habían causado el abatimiento comercial de San Sebastián desde 1808. Achacaban el abatimiento del comercio de San Sebastián a la prohibición de entrada de productos extranjeros por mar y de extracción de coloniales hacia Navarra. Los autores se quejaban de las facilidades que tenían los franceses, quienes se trasladaban a las colonias y extraían los productos coloniales para luego llevarlos a sus puertos, entre ellos Bayona, desde donde por tierra los introducían en Navarra libremente, mientras San Sebastián lo tenía prohibido. San Sebastián tuvo libertad de giro para introducir coloniales hasta 1808, momento en que «...con los trastornos y novedades que ha habido, desapareció aquella justa libertad que disfrutaba y se trasladó todo el giro del comercio a los Bayoneses, de lo que resulta la total ruina de San Sebastián.». Solicitaban así mismo la habilitación de San Sebastián para el comercio con América, pero sin situar aduana en su puerto y pagando al menos los mismos aranceles que pagaban los franceses; en este apartado se mencionaba que a una casa de comercio -aunque desgraciadamente no se especifica cuál- le estaba concedido desde hacía años poder recibir libremente desde América cacao e introducirlo en Castilla y Aragón, pagando en Vitoria los derechos reales. Demandaban la intervención de las autoridades provinciales para obtener de la Corona las mismas facilidades que tenían anteriormente en la introducción de productos coloniales sin recargo de ningún derecho, cuando estuviesen destinados al consumo de las provincias exentas y Navarra, pagando en Vitoria los derechos de aquellos productos destinados a la península ${ }^{22}$. Entre los firmantes de dicha relación encontramos un grupo ciertamente heterogéneo de comerciantes: grandes comerciantes como Bernado Alcain-Garro, comerciantes medianos como Miguel de Gascue, Juan Ibar, Simón de Iturralde, José Lorenzo de Labaca o José Fermín Minondo, dedicados al comercio de coloniales y de tabaco -aunque a menor escala que los Brunet, Queheille o Collado-, y pequeños comerciantes como Antonio Sasiain o Antonio Erausquin.

CUADRO 2: FIRMANTES DE LA RELACIÓN SOBRE EL ABATIMIENTO DEL COMERCIO DE SAN SEBASTIÁN (5-VII-1833)

\begin{tabular}{|c|c|}
\hline Alcain, Bernardo & Alsua, Manuel \\
\hline Cidalceta, Gerónimo & Echaniz, Ignacio María de \\
\hline Echeverría y Benito & Echeverría, Juan Gregorio de \\
\hline Eraña, Manuel de & Erausquin, Antonio \\
\hline
\end{tabular}

22 AGG-GAO, JD AJI 10,7. AGG-GAO, AGAM-EU-A-00004, fol. 47 r $^{\circ}-49$ vo 


\begin{tabular}{|c|c|}
\hline Gascue, Miguel de & Goenaga, José \\
\hline Ibar, Juan & Iturralde, Simón de \\
\hline Labaca, José Lorenzo de & Labroche, Viuda de \\
\hline Lasquibar, Miguel José de & Mendoza, Antonio de \\
\hline Minondo, José Fermín de & Sasiain, Antonio \\
\hline Villanueva, Juan Esteban & Zavaleta, Juan Miguel \\
\hline
\end{tabular}

Fuente: AGG-GAO, JD AJI 10,7. AGG-GAO, AGAM-EU-A-00004, fol. 47 r $-49 \mathrm{v}^{\mathrm{o}}$.

La suspensión de la habilitación de San Sebastián decretada en 1833, fue resuelta en Real Orden publicada el 16 de enero de 1836, en plena Guerra Carlista, por la que se mandaba llevar a efecto definitivamente lo decretado en 1832, como premio al apoyo de San Sebastián a la causa isabelina. Tras el Convenio de Vergara y el final del conflicto bélico, los comerciantes de San Sebastián se fueron acercando a sus objetivos, aunque con pequeñas demoras. El 16 de noviembre de 1839 se confirmaba la ley de 25 de octubre del mismo año, y con ella los fueros guipuzcoanos, se restauraba la organización administrativa foral, se trasladaban las aduanas nuevamente al interior y se restablecía la calidad de hidalguía para ser elector o elegible, todo lo cual fue un duro golpe para el sector a favor de la habilitación. En respuesta, el Ayuntamiento y la Junta de Comercio decidieron encargar a una comisión un informe sobre la cuestión aduanera. Sin embargo, la discusión de tal informe en una junta de vecinos puso de manifiesto la división interna existente en su seno. Un sector de la burguesía de San Sebastián, compuesta esencialmente por medianos y pequeños comerciantes se opuso a una reforma, en su opinión, tan radical como el traslado de aduanas. De todas formas, como protesta a la confirmación de la ley de 25 de octubre, treinta y nueve de los cuarenta y nueve hidalgos de San Sebastián firmaron una representación a la Reina en la que renunciaban a sus derechos como vecinos concejantes y pedían que se hicieran extensivos a todos los que debieran ejercerlos según la Constitución vigente $^{23}$. Curiosamente, entre los firmantes de esa representación se hallaban algunos de los que días después enviarían a la Reina otra representación, pero esta vez para solicitar la inhabilitación de San Sebastián y el traslado de aduanas al interior: José Luís Vidaurreta, José Vicente de Obineta y Manuel de Ureta.

23 LARRÍNAGA RODRÍGUEZ, 21 (Murcia, 2005): 337-344. RUBIO POBES, 1996a: 48-60. 
CUADRO 3: HIDALGOS FIRMANTES DE LA REPRESENTACIÓN A LA REINA (27-XI-1839)

\begin{tabular}{|c|c|c|}
\hline Alcain, Bernardo & Alcain, Manuel Joaquín de & Alzate, Lorenzo de \\
\hline Apalategui, Pedro Ignacio & Arambarri, José de & Arambarri, Juan Ramón de \\
\hline Aristeguieta, José de & Arizmendi, José Joaquín de & Arzac, José Francisco \\
\hline Brunet, Fernando de & Brunet, José & Brunet, José Manuel \\
\hline Collado, Cayetano & Collado, José Manuel de & Collado, Pablo \\
\hline Echagüe, Dionisio de & Echagüe, Evaristo & Echagüe, Joaquín Gregorio \\
\hline Echagüe, Joaquín Vicente & Eraunzeta, José Antonio de & $\begin{array}{c}\text { Fernández de Garayalde, } \\
\text { José Antonio }\end{array}$ \\
\hline Gil Alcain, Angel & Goicoa, Juan Ramón de & José Ignacio de Vidaurre \\
\hline Legarda, José Elías de & Mendizábal, Joaquín de & Obineta, José Vicente de \\
\hline Olañeta, José María de & Olarreaga, José Antonio de & Orbegozo, José Domingo \\
\hline Quemes, Luís Díez de & Saenz Izquierdo, José María & Sagasti, Joaquín de \\
\hline Soraiz, Francisco Javier de & Soraiz, Manuel Joaquín de & Ureta, Manuel de \\
\hline Vidaurreta, José Luis de & Yun, Joaquín & Yunibarbia, Manuel \\
\hline
\end{tabular}

Fuente: RUBIO POBES, 1996a: 57.

Seis años después y finalizada la guerra carlista, el sector que abogaba por la no habilitación y la permanencia de las aduanas en el interior volvió a hacer acto de presencia. El día 19 de diciembre de 1839 algunos de los mismos protagonistas de la Relación de 1833 o sus hijos, a los que se sumaron otros comerciantes, elevaron una nueva petición con similares argumentos. Concretamente, sesenta y seis comerciantes, al por mayor y al por menor, la gran mayoría medianos y pequeños comerciantes (relojeros, panaderos, tenderos, comerciantes, empresarios papeleros, etc.), enviaron una representación que contó con la aquiescencia y apoyo de la Diputación. Entre ellos destacaban apellidos como Gascue, Gros, Ibar, Labaca, Minondo u Olasagasti, todos ellos medianos comerciantes. Según Celia Aparicio Pérez los medianos y pequeños comerciantes de San Sebastián, presentaban una cartera de negocios similar a la de los grandes comerciantes, menor en volumen pero con una mayor diversidad. La mayor parte de ellos se dedicaba al tráfico colonial principalmente con Cuba, La Guaira y Caracas, aunque también esporádicamente con Valparaíso, Curazao, Puerto Rico, Trinidad y Tobago. Veamos algunos ejemplos. 
CUADRO 4: FIRMANTES DE LA REPRESENTACIÓN ENVIADA A LA REINA GOBERNADORA (19-XII1839)

\begin{tabular}{|c|c|c|}
\hline Achucarro, Juan Antonio & Altuna, Luis & Alzua, viuda de \\
\hline Ascune, Miguel de & Ayani, Jon & Bastida, José María de \\
\hline Bidaurreta, José Luis & Brochetón, Luis & Cigorraga, Ceferino de \\
\hline Dauphin & Domercq, Juan & Echaniz, Ignacio María \\
\hline Echeverría, Dionisio de & Echeverría, Francisca & $\begin{array}{c}\text { Echeverría, José Gregorio } \\
\text { de }\end{array}$ \\
\hline Eraña, Manuel de & Gascue, Ángel María de & Gascue, Francisco Javier \\
\hline Gros, José & Guereca, Juan José de & Ibar, Juan \\
\hline Insausti, José Antonio & Insausti, Juan Manuel & Iturbide, José Domingo de \\
\hline Labaca, José Lorenzo & Levas freres & Mercader, Manuel \\
\hline Minondo, José & Montel, María Antonia & Nerecan, Ignacio \\
\hline Obineta, José Vicente de & Olasagasti, Domingo de & Olasagasti, Tomás de \\
\hline Petitjean & Recalde, Esteban de & Rodríguez, Francisco \\
\hline Toral, Antonio de & Ureta, Manuel de & Urruzola, Juan Ignacio de \\
\hline Vidaurre, Martín de & Zidalceta, Jerónimo de & \\
\hline
\end{tabular}

Fuente: INSAUSTI, 4 (San Sebastián, 1970): 282-283. AGG-GAO, JD AJI 10, 7. AGG-GAO, JD AJI 11, 2. AGG-GAO, JD IM 2/22/97.

Juan Ibar, de origen bearnés, natural de Tardets donde nació en 1771, en el obispado de Olorón, hijo de Pedro de Ibar y de Juana Beloc, se trasladó a Guipúzcoa como criado de Pablo Carrese, también bearnés afincado en Tolosa. Habiendo recibido de Juan Antonio Carrese, vecino de Tolosa e hijo del mencionado Pablo Carrese, el molino de Arterreca, estableció allí la primera fábrica de papel en Guipúzcoa hacia 1803, para posteriormente establecer otra en Azaldegui en Ibarra. La fábrica de Ibarra fue quemada por los guerrilleros guipuzcoanos en 1812, momento en que Juan Ibar se trasladó a San Sebastián, donde ya le encontramos en 1817 afincado en el barrio de Santa Catalina, dedicado a su actividad comercial. En la ciudad donostiarra fue administrador del Excusado para la Compañía de Comercio de los Cinco Gremios Mayores de Madrid, compró algunas fincas, se dedicó a la confección y al comercio de remos. A decir de Isabel Mugartegui, las casas comerciales de Miguel Gascue y Juan Ibar fueron de las más solventes en la San Sebastián del período 1800-1840, repartiendo sus inversiones esencialmente entre el comercio $(66,3 \% \text { y } 40 \% \text { ) y los bienes raíces (12 y } 35 \%)^{24}$. Estos comercian-

24 APARICIO PÉREZ, 1991: 389. INSAUSTI, 4 (San Sebastián, 1970): 279-281. MUGARTEGUI EGUÍA, 4 (San Sebastián, 2003): 388. 
tes medianos tenían grandes similitudes con los grandes comerciantes de San Sebastián, pues como aquellos también realizaban sus transacciones a través de navíos franceses, sobre todo procedentes de Burdeos y Bayona, aunque muchos eran copropietarios o tenían participación en dichas naves, como es el caso de los hermanos Minondo, quienes además de ser capitulares del Ayuntamiento -José Minondo fue regidor en los ayuntamientos constitucionales de 1837,1842 y $1843-1844-$, eran armadores que fletaban la mayor parte de sus viajes a Cuba. Además del comercio ultramarino, otra de las áreas de actuación era la de los intercambios con la península y Europa, aunque a menor escala que los grandes comerciantes: en la península, Navarra, Aragón, Madrid, Santander, Galicia, Sevilla Cádiz y Bilbao; en Europa, Burdeos y, esporádicamente, París, Nantes, Bruselas o los puertos ingleses. Al igual que los grandes comerciantes, era habitual que actuasen como apoderados de firmas peninsulares y extranjeras; el famoso José Gros -que dio nombre a uno de los barrios de la ciudad, donde tenía su habitación y fábricas de sidra y puntas de París-, además de estar matriculado como confitero, fue síndico en los ayuntamientos constitucionales de 1848-1851 y regidor en el de 1854-1855, apoderado de la compañía parisina Gallou y de comerciantes españoles como Felipe Boye o Vicente Parga. De forma más esporádica y con una relativa rentabilidad, también se dedicaron al suministro del ejército ${ }^{25}$.

Volviendo a la mencionada representación de 1839, los firmantes criticaban la novedad que intentó introducir en el año 1824 el contador de reglamentos y Juez interino de Contrabando, pedían la vuelta al capitulado de 1727 y por tanto la restitución a Guipúzcoa de «...su libertad pactada en el Capitulado para traer con franqueza desde los puertos extranjeros y de las Américas el cacao, azúcar, canela, chocolate y bainilla para el consumo de sus habitadores será un acto de justicia bien propio de Vuestra Majestad: permitir el paso de estos mismos géneros a Navarra para el surtido de aquel país, una gracia que, disfrutada ahora exclusivamente por los franceses, no puede negarse a vuestros mas humildes súbditos; y habilitarles para su importación en Castilla y Aragón...», siendo aplicada a las colonias emancipadas, habilitar el puerto de San Sebastián para el resto de posesiones coloniales, la libertad de extracción de coloniales hacia Navarra, como ya se hiciera en 1793, derogando la disposición de 1786, y hacia Castilla y Aragón, pagando los correspondientes aranceles. Volvían, una vez más, a echar mano del tan manido argumento relacionado con Bayona, «...porque consumiendo esclusivamente los de Francia, a donde la arriería para su compra y adquisición nada puede aportar, sino dinero, empobrece a la Nacion sacando la moneda: porque el tráfico de los Franceses prospera, aniquilando el de estas Provincias: porque Bayona medra,

\footnotetext{
25 APARICIO PÉREZ, 1991: 233-238; 375-387.
} 
mientras San Sebastian y su marineria perece...». Para terminar, negaban que el status quo fomentase el contrabando, puesto que «...la esperiencia demuestra que por otras Provincias se ha contrabandeado y contrabandea escandalosamente, sin que aquellas tengan las esenciones que estas... $\rangle^{26}$.

CUADRO 5: FIRMANTES ADHERIDOS A LA REPRESENTACIÓN ANTE LA REINA GOBERNADORA (23XII-1839)

\begin{tabular}{|l|l|l|}
\hline Aguirre, Viuda de & Aldabe, Viuda de & Arocena hijo, Viuda de \\
\hline Arrache, Lucas & Arrieta, Juana Bautista & Azpiroz, Juana \\
\hline Barech, Pedro & Betelu, José Antonio de & Egues, Domingo \\
\hline Elosegui, Joaquín Antonio de & Erquiaga, Pascual de & Garín, Antonio \\
\hline Goñi, Pedro & Goya, Viuda de & Izaguirre, Concepción \\
\hline Jáuregui, Fermín & Lete, Ignacio & Machilanda, Tomasa \\
\hline Satrústegui, Viuda de & Zavala José Antonio de & Zavala, Juan Antonio de \\
\hline Zornoza, Antonio & & \\
\hline
\end{tabular}

Fuente: AGG-GAO, JD IM 2/22/97.

Una Real Orden de 20 de diciembre de 1839 permitió al Ayuntamiento donostiarra renovarse según la normativa constitucional. Por último, el 23 de diciembre de 1839, una serie de comerciantes, la mayoría al por menor, se adhirieron, puesto que en su momento no pudieron hacerlo, a la Representación del 19 de diciembre. Entre dichos comerciantes encontramos asimismo medianos y pequeños comerciantes de la ciudad ${ }^{27}$.

La mayor parte de los firmantes de las representaciones de 1833 y 1839 , opuestos a la habilitación y al traslado de aduanas a la costa, fueron capitulares del Ayuntamiento donostiarra en la primera mitad del siglo XIX. Aunque alguno de ellos, como Miguel Gascue, fue alcalde y, junto a Bernardo AlcainGarro y Simón de Iturralde, teniente de alcalde, la mayor parte ocupó cargos de regidor, síndico o diputado del común. Llama la atención, sin duda, la presencia en 1833 de Bernardo Alcain-Garro, por ser miembro de una de las familias de grandes comerciantes de San Sebastián y ser su hermano, Ángel Gil Alcain, uno de los que apoyará las iniciativas consulares para la obtención de la habilitación y el traslado de aduanas. Esto demuestra que más allá de grandes o medianos y pequeños comerciantes, la disparidad de pareceres era algo

26 INSAUSTI, 4 (San Sebastián, 1970): 282-283. AGG-GAO, JD AJI 10, 7. AGG-GAO, JD AJI 11, 2. AGG-GAO, JD IM 2/22/97. Por su parte, Coro Rubio Pobes habla de una burguesía monolítica enfrentada toda ella a la Provincia. RUBIO POBES, 1996b: 99.

27 Al respecto véase la lista proporcionada por APARICIO PÉREZ, 1991: 233-238. 
personal y que seguramente también dependió de la situación por la que atravesó en cada momento cada una de las casas de comercio y negocios. A excepción de alguno como Vicente Obineta, que formó parte de los Tercios realistas, la mayoría estuvo enrolada en las Milicias nacionales y formó parte de los ayuntamientos liberales durante el Trienio Liberal o la Primera Guerra Carlista, lo cual casa difícilmente con la asociación que habitualmente se hace entre librecambismo o liberalismo económico y liberalismo político, puesto que aunque formaron parte de ayuntamientos de corte liberal estaban en contra de la habilitación y el traslado de aduanas.

CUADRO 6: CARGOS CONCEJILES OCUPADOS POR LOS COMERCIANTES DISIDENTES (1813-1855)

\begin{tabular}{|c|c|c|c|c|c|c|}
\hline NOMBRE & ALCALDE & $\begin{array}{l}\text { TENIENTE } \\
\text { AlcaldE }\end{array}$ & REGIDOR & $\begin{array}{l}\text { TENIENTE } \\
\text { REGIDOR }\end{array}$ & SíNDICO & $\begin{array}{l}\text { DipUTADO } \\
\text { COMÚN }\end{array}$ \\
\hline $\begin{array}{l}\text { Alcain, } \\
\text { Bernardo }\end{array}$ & & 1846 & $\begin{array}{l}1837 \\
1841 \\
1848 \\
\end{array}$ & & & \\
\hline $\begin{array}{l}\text { Echeverría, } \\
\text { Dionisio }\end{array}$ & & & $\begin{array}{c}1837 \\
1846-1847 \\
1854-1855 \\
\end{array}$ & & & \\
\hline $\begin{array}{l}\text { Echeverría, } \\
\text { Juan Gregorio }\end{array}$ & & & $\begin{array}{l}1822 \\
1823\end{array}$ & & & \\
\hline $\begin{array}{l}\text { Eraña, } \\
\text { Manuel }\end{array}$ & & & & & $\begin{array}{l}1820 \\
1821 \\
\end{array}$ & \\
\hline $\begin{array}{l}\text { Gascue, Án- } \\
\text { gel María }\end{array}$ & & $\begin{array}{l}1850-1851 \\
1854-1855\end{array}$ & & & & \\
\hline $\begin{array}{c}\text { Gascue, } \\
\text { Francisco } \\
\text { Javier }\end{array}$ & & & $\begin{array}{l}1844-1845 \\
1854-1855\end{array}$ & 1833 & & \\
\hline $\begin{array}{l}\text { Gascue, Mi- } \\
\text { guel }\end{array}$ & 1820 & 1831 & 1813 & & & \\
\hline $\begin{array}{l}\text { Goenaga, } \\
\text { José }\end{array}$ & & & $\begin{array}{l}1837 \\
1840 \\
1841\end{array}$ & & 1822 & 1827 \\
\hline $\begin{array}{l}\text { Iturralde, } \\
\text { Simón }\end{array}$ & & $\begin{array}{c}1828 \\
1832 \\
1834-1835 \\
\end{array}$ & 1820 & & & \\
\hline $\begin{array}{c}\text { Labaca, José } \\
\text { Lorenzo }\end{array}$ & & & 1820 & & $\begin{array}{l}1823- \\
1826 \\
\end{array}$ & \\
\hline $\begin{array}{l}\text { Mercader, } \\
\text { Manuel }\end{array}$ & & & $\begin{array}{l}1843-1844 \\
1848-1849\end{array}$ & & & \\
\hline $\begin{array}{c}\text { Olasagasti, } \\
\text { Domingo }\end{array}$ & & & $1813-1814$ & & & \\
\hline
\end{tabular}




\begin{tabular}{|c|c|c|c|c|c|c|}
\hline NOMBRE & ALCALDE & $\begin{array}{l}\text { TENIENTE } \\
\text { ALCALDE }\end{array}$ & REGIDOR & $\begin{array}{l}\text { TENIENTE } \\
\text { REGIDOR }\end{array}$ & SÍNDICO & $\begin{array}{c}\text { DIPUTADO } \\
\text { COMÚN }\end{array}$ \\
\hline $\begin{array}{l}\text { Olasagasti, } \\
\text { Tomás }\end{array}$ & & $1846-1847$ & $\begin{array}{l}1843-1844 \\
1848-1849\end{array}$ & & & \\
\hline $\begin{array}{l}\text { Obineta, } \\
\text { Vicente }\end{array}$ & & & & $\begin{array}{l}1834- \\
1835 \\
\end{array}$ & & \\
\hline $\begin{array}{c}\text { Urruzola, } \\
\text { Juan Ignacio }\end{array}$ & & & & 1832 & $\begin{array}{l}1854- \\
1855\end{array}$ & \\
\hline $\begin{array}{c}\text { Zidalceta, } \\
\text { Jerónimo }\end{array}$ & & & 1820 & & & 1828 \\
\hline
\end{tabular}

Fuente: elaboración propia a partir de los datos aportados por APARICIO PÉREZ, 1991: 365-387.

\section{CONCLUSIONES}

En definitiva, el debate en torno a la habilitación del puerto de San Sebastián y el traslado de aduanas a la costa y la frontera del territorio no tuvo como protagonistas únicamente a dos bloques perfectamente tipificados, los comerciantes y burgueses donostiarras, representados por el concejo y Consulado, primero, y el Ayuntamiento y la Junta de Comercio, después, y la nobleza rural, representada por la Diputación y las Juntas Generales. En realidad, dentro del grupo de comerciantes de San Sebastián existió una heterogeneidad de posturas con respecto a la mencionada cuestión. Entre los siglos XVIII y XIX los discursos se fueron clarificando, radicalizando y completando, en función de las cambiantes circunstancias: desde la mera petición de habilitación para el puerto de San Sebastián, pero el rechazo al traslado de aduanas, hasta llegar a considerar una prioridad el traslado de aduanas, por encima de la habilitación. Ya en el siglo XIX, cuando los discursos estaban bien clarificados, encontramos, por un lado, a una minoría de grandes comerciantes representados por ilustres familias como los Brunet, Queheille, SerresLaffite, Collado y Lasala, Echagüe o Bermingham, que controlaban tanto el Ayuntamiento como el Consulado y la Junta de Comercio, protagonistas de los denodados y prolongados intentos por, primero, habilitar el puerto de San Sebastián para el comercio directo con América, y después, por trasladar las aduanas a la $\operatorname{costa}^{28}$. Por otro lado, se sitúa -con la excepción de los AlcainGarro, también grandes comerciantes- una gran mayoría de medianos y pequeños comerciantes, como los Gascue, Ibar, Gros, Minondo, Labaca u Olasagasti, que ocuparon generalmente puestos importantes en el Ayuntamiento, aunque se vieron desplazados del Consulado y la Junta de Comercio.

28 Sobre estos clanes mercantiles véase APARICIO PÉREZ, 1991: 195-218. GÁRATE OJANGUREN, 24 (San Sebastián, 1990): 105-134. 
Este grupo coincidió con las máximas defendidas por las autoridades provinciales, contrarias a la habilitación del puerto de San Sebastián y al traslado de aduanas a la costa y la frontera, porque lesionaba sus intereses e inversiones. Ambos grupos tenían inversiones similares y accedían a los mismos mercados; pero la gran diferencia fue el volumen de negocio y la variedad de productos y actividades mercantiles. Los medianos y pequeños comerciantes, que desarrollaban negocios de menor volumen, pero mayor diversidad, se encontraban cómodos en el status quo, puesto que sus patrimonios e inversiones, precisamente por esa doble característica, tenían un índice de riesgo menor y una mayor protección. Pudo existir también otra razón de peso: estos comerciantes producían personalmente o accedían en los mercados locales a algunos de los productos que comercializaban; industrias todas ellas de escasa estructura financiera que precisaban de la defensa de las aduanas y del sistema foral para evitar la competencia exterior. Sin embargo, los grandes comerciantes dependían exclusivamente del comercio de coloniales, un comercio por otro lado de intermediación o tránsito ${ }^{29}$, no de producción-comercialización, por lo que indefectiblemente, necesitaban la habilitación del puerto de San Sebastián y el traslado de aduanas a la costa, para españolizar dichos productos, y que su balanza de pagos y gastos no se viese perjudicada por el cobro de derechos. Ambas medidas, como efectivamente ocurriría en otros puertos como Bilbao y ya advirtieron los comisionados de las Juntas Generales de Azpeitia que tuvieron que analizar la exposición del Ayuntamiento y la Junta de Comercio donostiarras en 1831, perjudicaban a los mediados y pequeños comerciantes; de ahí su frontal oposición a los grandes comerciantes. No obstante, se debe huir del excesivo encasillamiento que pudiera suponer la consideración de los mercaderes opuestos a dichas medidas como medianos y pequeños comerciantes, puesto que los casos de Bernardo Alcain-Garro o Juan Ibar demuestran que, más allá de etiquetas, lo que condicionó en cada momento la posición de cada uno de los comerciantes donostiarras fueron factores personales, familiares y económicos de difícil generalización. En definitiva, el debate sobre la habilitación del puerto de San Sebastián y el traslado de aduanas a la costa y frontera tuvo un carácter ciertamente heterogéneo y dispar hasta que finalmente en 1841 se decretaran definitivamente ambas medidas.

29 A este respecto son de gran interés la palabras de Montserrat Gárate: «...la burguesía mercantil donostiarra apenas estaba interesada en los procesos productivos del Pais; el intercambio de productos era su objetivo económico, y la situación geográfica de su puerto, junto con las franquicias de que gozaban, alentaron aún más esta postura». GARATE OJANGUREN, 9-10 (Bilbao, 1988): 46-47; 53-54. 


\section{BIBLIOGRAFIA}

Alberdi Lonbide, Xavier, Conflicto de intereses en la economía marítima guipuzcoana. Siglos XVI-XVIII, Bilbao, UPV, 2006.

Aparicio Pérez, Celia, Poder municipal, economía y sociedad en la ciudad de San Sebastián (1813-1855), San Sebastián, Kutxa, 1991.

Aragón Ruano, Álvaro, “«Con casa, familia y domicilio». Mercaderes extranjeros en Guipúzcoa durante la Edad Moderna”, Stvdia Historica. Historia Moderna, 31 (Salamanca, 2009a): 155-200.

Aragón Ruano, Álvaro, La ganadería guipuzcoana durante el Antiguo Régimen, Bilbao, UPV, 2009b.

Arazola Corvera, María Jesús, "El mundo del comercio vasco-navarro en la ruta del Plata. Los registros sueltos", Itsas Memoria. Revista de Estudios Marítimos del País Vasco, 4 (San Sebastián, 2003): 327-342.

Astiazarán Achabal, María Isabel, El Consulado de San Sebastián y los proyectos de ampliación de su puerto en el siglo XVIII, San Sebastián, Kutxa, 1998.

Astigarraga, Jesús, Los Ilustrados Vascos. Ideas, instituciones y formas económicas en España, Barcelona, Crítica, 2003.

Díaz Trechuelo, Lourdes, La Real Compañia de Filipinas, Sevilla, 1965.

Domínguez, Cristina, Etxeberria, Marisol, Gamecho, Maria Asunción, "La Sociedad de Amigos del País de San Sebastián de 1779: ¿Un proyecto enfrentado a la Bascongada?", en II Seminario de Historia de la Real Sociedad Bascongada de los Amigos del País, San Sebastián, RSBAP, 1988; 239-270.

Extractos de las Juntas Generales celebradas por la Real Sociedad Bascongada de Amigos del País en la villa de Bilbao por setiembre de 1778, Vitoria, Tomás Robles y Navarro, 1779.

Fernández Albaladejo, Pablo, La crisis del Antiguo Régimen en Guipúzcoa, 17661833: cambio económico e historia, Madrid, Akal, 1975.

Fernández de Pinedo, Emiliano, Crecimiento económico y transformaciones sociales del País Vasco, 1100-1850, Madrid, Siglo XXI, 1974.

Fernández de Pinedo, Emiliano, "Comercio y colonias (1770-1850). El papel de Guipúzcoa”, Revista de Dirección y Administración de Empresas, 2 (San Sebastián, 1995): 55-66.

Fisher, John Robert, “Comercio libre entre Andalucía y América, 1778-1796”, en Bibiano Torres Ramírez, José Javier Hernández Palomo, Andalucía y América en el siglo XVIII: actas de las IV Jornadas de Andalucía y América, Vol. 1, Huelva, Universidad de Santa María de la Rábida, 1985; 37-58.

Fisher, John Robert, "El impacto del comercio libre en América durante el último cuarto dle siglo XVIII", en Antonio Miguel Bernal (coord.), El "Comercio libre” entre España y América (1765-1824), Madrid, Fundación Banco Exterior, 1987; 29-38.

Gárate Ojanguren, Montserrat, El proceso de desarrollo económico en Guipúzcoa, San Sebastián, Cámara de Comercio, Industria y Navegación de Guipúzcoa, 1976. 
Gárate Ojanguren, Montserrat, "Comercio, burguesía y acumulaciones de capital en el País Vasco (1700-1841)”, Ekonomíaz, 9-10 (Bilbao, 1988): 35-54.

Gárate Ojanguren, Montserrat, La Real Compañía de Caracas, San Sebastián, Doctor Camino, 1990a.

Gárate Ojanguren, Montserrat, "La familia Brunet, San Sebastián y América (Presencia catalana en el puerto donostiarra, s. XVIII-XIX)", Boletín de Estudios Históricos sobre San Sebastián, 24 (San Sebastián, 1990b): 105-134.

Gárate Ojanguren, Montserrat, Comercio Ultramarino e Ilustración. La Real Compañia de la Habana, San Sebastián, Real Sociedad Bascongada de Amigos del País, 1993.

Goñi Galárraga, Joseba, "La Revolución francesa en el País Vasco: la Guerra de la Convención (1793-1795)", en Historia del Pueblo Vasco, 3, San Sebastián, Erein, $1979 ; 5-69$.

Goñi Galarraga, Joseba, "Imagen política del País Vasco en algunos documentos franceses de la Guerra de la Convención (1793-1795), en Historia del País Vasco (siglo XVIII), Bilbao, Universidad de Deusto, 1985; 247-294.

Insausti, Sebastián, "Apuntes para la historia comercial donostiarra. Un clan de comerciantes zuberoarras: Pablo Carrese Barrullet”, Boletín de Estudios Históricos de San Sebastián, 4 (San Sebastián, 1970): 273-288.

Jaupart, Fernand, L'Activité Commérciale et Maritime de Bayonne au XVIII siècle, 2 vols., Bayona, Darracq, 1966-1974.

Larrínaga Rodríguez, Carlos, "Comercio con América y traslado de aduanas. El nacimiento del liberalismo económico en Guipúzcoa en la primera mitad del siglo XIX”, Anales de Historia Contemporánea, 21 (Murcia, 2005): 323-344.

Llanos Aramburu, Félix, El Trienio Liberal en Guipúzcoa (1820-1823). Antecedentes de las Guerras Carlistas en el País Vasco, San Sebastián, Universidad de Deusto, 1998.

Miguel López, Isabel, ""Aldaz": Sociedad mercantil donostiarra del siglo XVIII", Boletín de Estudios Históricos sobre San Sebastián, 39 (San Sebastián, 2005): 237-286.

Mugartegui Eguía, Isabel, "Incentivos y dificultades para la inversión del capital mercantil en Guipúzcoa, siglos XVIII y XIX: una comparación con la clase propietaria”, Itsas Memoria. Revista de Estudios Maritimos del País Vasco, 4 (San Sebastián, 2003): 383-396.

Otazu y Llana, Alfonso, La burguesía revolucionaria vasca a fines del siglo XVIII, San Sebastián, Txertoa, 1982.

Pontet-Fourmigue, Josette, Bayonne, un destin de ville moyenne à l'époque Moderne (fin du XVIIe siècle, milieu du XIXe siècle), Biarritz, J et D, 1990.

Pontet-Fourmigue, Josette, "Bayonne, port moyen à l'époque moderne", en Michèle Collin (dir.), Ville et port XVIIIè-XXè siècles, Paris, L’Harmattan, 1994; 25-41. 
Portillo Valdés, José María, "Las provincias vascas y la Guerra de la Convención: primer encuentro con la Revolución", Stvdia Histórica. Historia Moderna, 12 (Salamanca, 1994): 71-90.

Rubio Pobes, Coro, Memoria justificativa de San Sebastián para el fomento de la industria y el comercio de Guipúzcoa (1832), Bilbao, UPV, 1996.

Rubio Pobes, Coro, Revolución y tradición. El País Vasco ante la Revolución liberal y la construcción del Estado español, 1808-1868, Madrid, Siglo XXI, 1996b.

Soria Sesé, Lourdes, "La controversia sobre los supuestos abusos del sistema aduanero vasco: 1795-1829”, Notitia Vasconiae, 2 (San Sebastián, 2003): 453-480.

Recibido: 05-10-2011

Aceptado: 30-07-2012 